Key Words:

$M C U$,

Solvent Extraction

Retention: Permanent

Sodium Aluminosilicate Solids Affinity for Cesium and Actinides

\author{
T. B. Peters
}

W. R. Wilmarth

S. D. Fink

July 31, 2007 
This document was prepared in conjunction with work accomplished under Contract No. DEAC09-96SRI8500 with the U. S. Department of Energy.

\section{DISCLAIMER}

This report was prepared as an account of work sponsored by an agency of the United States Government. Neither the United States Government nor any agency thereof, nor any of their employees, nor any of their contractors, subcontractors or their employees, makes any warranty, express or implied, or assumes any legal liability or responsibility for the accuracy, completeness, or any third party's use or the results of such use of any information, apparatus, product, or process disclosed, or represents that its use would not infringe privately owned rights. Reference herein to any specific commercial product, process, or service by trade name, trademark, manufacturer, or otherwise, does not necessarily constitute or imply its endorsement, recommendation, or favoring by the United States Government or any agency thereof or its contractors or subcontractors. The views and opinions of authors expressed herein do not necessarily state or reflect those of the United States Government or any agency thereof. 


\section{APPROVAL}

\section{Author:}

T. B. Peters, Separations Science Programs Date

W. R. Wilmarth, Process Chemistry \& Science

Date

\section{Design Check:}

M. R. Poirier, Separations Science Programs

Date

\section{Customer:}

K. P. Burrows, MCU Design Authority

Date

E. A. Brass, MCU Design Authority

Date

\section{Management:}

S. D. Fink, Separations Science Programs Manager Date

A. M. Murray, Actinide and Chemical

Date Technology Section Manager 


\title{
Sodium Aluminosilicate Solids Affinity for Cesium and Actinides
}

\author{
T. B. Peters, W. R. Wilmarth, and S. D. Fink
}

\begin{abstract}
Washed sodium-aluninosilicate (NAS) solids at initial concentrations of 3.55 and $5.4 \mathrm{~g} / \mathrm{L}$ sorb or uptake virtually no cesium over 288 hours, nor do any NAS solids generated during that time. These concentrations of solids are believed to conservatively bound current and near-term operations. Hence, the NAS solids should not have affected measurements of the cesium during the mass transfer tests and there is minimal risk of accumulating cesium during routine operations (and hence posing a gamma radiation exposure risk in maintenance). With respect to actinide uptake, it appears that NAS solids sorb minimal quantities of uranium - up to $58 \mathrm{mg} \mathrm{U}$ per kg NAS solid. The behavior with plutonium is less well understood. Additional study may be needed for radioactive operations relative to plutonium or other fissile component sorption or trapping by the solids. We recommend this testing be incorporated in the planned tests using samples from Tank $25 \mathrm{~F}$ and Tank $49 \mathrm{H}$ to extend the duration to bound expected inventory time for solution.
\end{abstract}

\section{INTRODUCTION}

During the initial operations at MCU (Modular Caustic-Side Solvent Extraction Unit), over a 10-hour operating period, the pressure drop over the coalescer element reached $\sim 10$ psi while processing some $\sim 1250$ gallons of salt solution, indicating possible fouling or clogging of the unit. This pressure drop is unacceptable for normal operations. To address the unexpected performance, MCU Design Authority, along with SRNL personnel developed a path forward. ${ }^{1,2}$ SRNL was tasked to determine the reason for the fouling, and define mitigating actions to avoid future problems in relation to the current testing as well as assessing how the behavior impacts long-term operation. Another document summarizes the initial examination of the clogged coalescer element. ${ }^{3}$ That document concluded that "changes in the temperature of the high silicate salt simulant accelerated the formation and precipitation of aluminosilicate ("NAS") compounds. These compounds were generated in enough quantity to foul the coalescer media to the point of a noticeable pressure drop. Once the current inventory of salt solution is filtered, kept in a temperature controlled environment and filtered on an intermediate basis, further instances of this problem should be eliminated."

If NAS solids are precipitating through the system, one concern is that they may bring radionuclides out of solution. This behavior would create a dose hazard if personnel are required to clean or replace parts of the MCU equipment. SRNL designed an experiment to determine if NAS solids sorb appreciable amounts of cesium. Also, SRNL assessed available literature to determine propensity for uptake of plutonium and uranium. 


\section{Experimental}

Cesium Uptake SRNL researchers generated two 100-mL solutions, each containing NAS solids. One solution contained $3.55 \mathrm{~g} / \mathrm{L}$ of NAS solids, and one contained $5.4 \mathrm{~g} / \mathrm{L}$. The $3.55 \mathrm{~g} / \mathrm{L}$ value was chosen to duplicate the amount of insoluble solids SRNL recovered from a Tanker-3 archive material. (Tanker 3 is the third of three tankers of salt solution received from the vendor. Operations personnel observed solids in that tanker after emptying and transferred a sample of the residual slurry to SRNL for analysis.) The $5.4 \mathrm{~g} / \mathrm{L}$ value was chosen as a conservative $50 \%$ increase from the $3.55 \mathrm{~g} / \mathrm{L}$ value. For the solids, we used filtered and washed solids from the MCU temporary modification filters ("Sample from inlet of filter housing 4-6-2007", delivered to SRNL at April 7, 2007). For the solution, we used freshly filtered ( $0.45 \mu$ m nylon filter cup) Tanker-3 archive liquid (delivered to SRNL on March 14, 2007). We also prepared a control solution consisting only of the filtered salt solution and cesium (i.e., with no added solids). To each of the stirring suspensions, we added enough cesium nitrate to make each solution $15 \mathrm{mg} / \mathrm{L}$ in cesium. We kept the solutions stirring and sampled three times over 288 hours. The samples were filtered using a $0.2 \mu \mathrm{m}$ syringe filter with the filtrates sent to ICPMS (Inductively-Coupled Plasma Mass Spectroscopy) for analysis of cesium. Table 1 lists the results. The analytical uncertainty is $20 \%$.

Table 1. Cesium Filtrate Concentration over Time

\begin{tabular}{|lcccc|}
\hline $\begin{array}{l}\text { test } \\
\text { ID }\end{array}$ & $\begin{array}{c}\text { Solids } \\
\text { Conc. (g/L) }\end{array}$ & $\begin{array}{c}\text { Cs 1 hour } \\
\text { result (ppm) }\end{array}$ & $\begin{array}{c}\text { Cs 24 hour } \\
\text { result (ppm) }\end{array}$ & $\begin{array}{c}\text { Cs 288 hour } \\
\text { result (ppm) }\end{array}$ \\
\hline 1 & 3.55 & 14.9 & 14.6 & 14.7 \\
2 & 5.4 & 14.2 & 14.4 & 14 \\
control & 0 & 14.6 & 14.9 & 14.8 \\
\hline
\end{tabular}

The results show no uptake of cesium by the solids either present during the beginning of the experiment, or by any solids generated over the 288 hours.

As a confirmation, the solids from each of the three solutions were removed via filtration ( $0.45 \mu \mathrm{m}$ nylon cup filter). The solids were digested and analyzed for cesium content. The results are listed in Table 2.

Table 2. Cesium Concentration in the Solids

\begin{tabular}{|c|c|c|c|}
\hline Test ID & $\begin{array}{c}\text { Solids Cesium } \\
\text { Concentration }(\mu \mathrm{g} / \mathrm{g})\end{array}$ & $\begin{array}{c}\text { Mass of Collected } \\
\text { Solids }(\mathrm{g})\end{array}$ & $\begin{array}{c}\text { \% of Added Cesium } \\
\text { Retained in the Solids }\end{array}$ \\
\hline 1 & 36.5 & 0.2436 & $0.63 \%$ \\
\hline 2 & 42.6 & 0.3521 & $1.01 \%$ \\
\hline control & 15.3 & 0.0382 & $0.040 \%$ \\
\hline
\end{tabular}


Digestion and analysis of the solids showed that there is minimal cesium content retained in the collected solids. It is quite possible that the cesium in the solids could be reduced further by washing.

Actinide Uptake Formation of aluminosilicate scales in the High Level Waste Evaporators at the Savannah River Site led to curtailed operation and an extensive cleaning evolution due in part, to the presence of enriched uranium in the scale. Several studies were undertaken to understand the ability of NAS solids to uptake uranium or other actinides. In one program, the researchers reported the sorption of plutonium as negligible with some sorption or trapping of uranium, especially from supersaturated solutions. ${ }^{4}$ The solutions tested do not bracket the current salt solution composition. The propensity for plutonium uptake will need to be assessed versus upcoming MCU experimental demonstrations for Tank $25 \mathrm{H}$ and Tank $49 \mathrm{H}$ samples to determine if additional experiments on actinide sorption are warranted. The assessment of the impact of NAS formation for radioactive operations in MCU is part of an ongoing review by a team chartered for this purpose.

Another program ${ }^{5}$ studied the sorption behavior of uranium species and sodium aluminosilicate (NAS) solid phases in nitrate/nitrite-rich sodium aluminosilicate solutions in a stainless steel beaker at $22^{\circ} \mathrm{C}$ with an agitation rate of $400 \mathrm{rpm}$. The study added NAS solids comprised of four well-characterized phases of amorphous, zeolite $\mathrm{A}$, sodalite and cancrinite. Pure, synthetic sodium diuranate $\left(\mathrm{Na}_{2} \mathrm{U}_{2} \mathrm{O}_{7}\right)$ crystals were precipitated and used as the base/reference Ucontaining compound. The uranium was added to solution to a concentration of $15 \mathrm{mg} / \mathrm{L}$. The studies of the sorption behavior of U-containing species on NAS solid phases were conducted under conditions where no detectable dissolution, precipitation or crystallographic phase transformation of the NAS adsorbent phases were observed over a 6-hour test period. The uranium sorption capacities were reached typically within three hours. The uranium capacities were measured 6.6 to $9.3 \mathrm{mg} \mathrm{U} \mathrm{kg}^{-1}$ NAS solid for the amorphous phase and the cancrinite phase. The same program of study found that the removal of $U$ species from its saturated solution is believed to be due to physisorption at specific NAS solid surface sites. Such favorable interactions may be largely attributed to physical forces such as van der Waals and electrostatic attraction in electrical double layer. Other mechanisms such as chemisorption (leading to alteration electronic structure modification), surface nucleation and isomorphous substitution may not be completely discounted, the observations made do not strongly support their consideration.

A separate document prepared by J. K. Jeffrey ${ }^{6}$ indicates that uranium loading for Zeolite A and sodalite phases has a higher uranium loading that measured between 9 and $58 \mathrm{mg} \mathrm{U} \mathrm{kg}^{-1} \mathrm{NAS}$ solid (0.0009 and 0.0058 wt \% respectively). However, even this higher loading is far less than the maximum infinite safe level of $0.12 \mathrm{wt} \%$. This document ascribes the high uranium maximum safe loadings due to saltcake poisoning form the NAS solids.

The same document from Jeffrey, and references therein ${ }^{7}$ describe the results from a study that looked at plutonium absorption onto cancrinite; one type of NAS. These studies indicated that 
cancrinite sorbed a maximum of plutonium to reach $0.00001 \mathrm{wt} \%$. The amount sorbed is based upon an analytical detection limit in that study.

Another study was done by Wilmarth in $2000 .^{8}$ This study measured the plutonium concentration in NAS solids collected from the $241-16 \mathrm{H}$ evaporator wall. A set of triplicate samples showed that the solids were $0.00773 \mathrm{wt} \%$ of the NAS solids. This concentration likely represents an upper bound as the evaporator is continuously introducing new aluminum and silicon, which drives further precipitation, which in turn can trap plutonium.

\section{CONCLUSIONS}

Washed NAS solids at initial concentrations of 3.55 and $5.4 \mathrm{~g} / \mathrm{L}$ sorb or uptake virtually no cesium over 288 hours, nor do any NAS solids generated during that time. These concentrations of solids are believed to conservatively bound current and near-term operations. Hence, the NAS solids should not have affected measurements of the cesium during the mass transfer tests and there is minimal risk for accumulating cesium during routine operations (and hence posing a gamma radiation exposure risk in maintenance). With respect to actinide uptake, it appears that NAS solids sorb minimal quantities of uranium - up to $58 \mathrm{mg} \mathrm{U} \mathrm{kg}^{-1} \mathrm{NAS}$ solid. The behavior with plutonium is less well understood. If the $0.00773 \mathrm{wt} \% \mathrm{Pu}$ loading is deemed to be unacceptably high, an additional study will be needed for radioactive operations relative to plutonium or other fissile components sorption or trapping by the solids. We recommend this testing be incorporated in the planned tests using samples from Tank $25 \mathrm{~F}$ and Tank $49 \mathrm{H}$ to extend the duration to bound expected inventory time for solution in MCU. 


\section{References}

1 C. I. Aponte, "Engineering Path Forward: MCU - Project Resolution of Solids Formation in Salt Simulant,” LWO-SPT-2007-00076, Rev. 0, April 16, 2007.

2 C. I. Aponte, "Engineering Path Forward: MCU - Project Resolution of Solids Formation in Salt Simulant,” LWO-SPT-2007-00076, Rev. 1, April 30, 2007.

3 T. B. Peters, M. R. Poirier, S. D. Fink, F. F. Fondeur, and A. R. Jurgensen, "Analysis of the Plugged Coalescer from MCU”, SRNL-CST-2007-00049, April 17, 2007.

${ }^{4}$ W. R. Wilmarth, J. T. Mills, V. H. Dukes, and R. C. Sullivan, "Effects of In-Tank Precipitation of Sodium Aluminosilicate on Uranium Chemistry," Separation Science and Technology, 41: 2325-2340, 2006.

${ }^{5}$ J. Addai-Mensah, J. Li, and M. Zbik, W. R. Wilmarth "Uranium Sorption on Solid Aluminosilicate Phases under Caustic Conditions," Separation Science and Technology, 40: 267, 2005.

${ }^{6}$ J. K. Jeffrey, “Nuclear Criticality Safety Assessment: Sorption of Fissile Material Onto Sodium Alumniosilicates”, N-ESR-G-2005-00007, January 28, 2005.

${ }^{7}$ L. N. Oji and D. T. Hobbs, "Identification of Tank 50H Solids Components Responsible for Removal of Dissolved Actinides”, WSRC-TR-2003-00554, January 2004.

${ }^{8}$ W. R. Wilmarth, C. J. Coleman, J. C. Hart, and W. T. Boyce, “Characterization of Samples from the 242-16H Evaporator Wall”, WSRC-TR-2000-00089, March 20, 2000. 